\title{
Fat emulsions for complete intravenous nutrition
}

\author{
D. Hallberg I. Holm A. L. Obel O. Schuberth A. Wrethind \\ King Gustav V Research Institute; Department of Surgery, St Gorans Hospital; Department of Surgery, \\ Serafimerlasarettet; Department of Anatomy and Pathology, State Veterinary Medical Institute; \\ and Department of Nutrition and Food Hygiene, National Institute of Public Health, Stockholm
}

AN ADEQUATE amount of food is important in order to maintain a patient in the best possible condition to stand such strains as disease or trauma of different kinds (infections, burn, surgery, etc.). If oral feeding is impossible the nutrients have to be given in some other way. The two possibilities available are tube feeding and intravenous nutrition. The intravenous route is employed when tube feeding is impossible.

Complete intravenous nutrition means the administration of adequate amounts of all the essential nutrients: protein or amino acids, fats, carbohydrates, electrolytes, vitamins and water.

The intravenous supply of water, carbohydrates, electrolytes and vitamins has been employed for many years without difficulty. The supply of protein can be covered by blood, plasma and/or amino acid solutions. To utilize the supplied amino acids in the synthesis of proteins and, concomitantly, to maintain body weight and normal body composition, it is necessary to supply also the other nutrients and calories required. It is difficult or, in many cases, even impossible to give a sufficient amount of calories in the form of amino acids, carbohydrates or alcohol. This is because too large a volume of fluid has to be provided when isotonic solutions are used. When hypertonic solutions are administered, vascular complications such as thrombophlebitis arise, and a hyperosmotic diuresis may also occur.

When parenteral nutrition has to be used it is possible to cover the caloric needs by means of fat emulsions given intravenously. The high caloric content of fat emulsion, containing $10-20 \%$ of fat, makes it possible to avoid the disadvantages associated with the large volumes or high concentrations required to cover the caloric need by other nutrients. The fat in the emulsion does not change the tonicity of the water phase. It can be infused into peripheral veins without causing vascular complications. The infusions do not produce a diuresis. Further, no losses are observed in the urine or the faeces. It is also possible that the fats in the emulsion contribute to the maintenance of the normal lipid composition of the body.

Fat was apparently first administered parenterally in 1869 (Wentzel \& Perco, 1869). After comprehensive animal experiments they gave subcutaneous injections of fat to a patient suffering from Pott's disease and in an emaciated condition. Hodder in Toronto used intravenous infusion of milk as a treatment for cholera in 1873 (Hodder, 1873). The first systematic attempts to administer artificial fat emulsion to man were carried out in Japan between 1920 and 1930. In the United States this subject was discussed, but nothing really useful was achieved, however, until 1950. In 1957 clinical and experimental results were published with a fat emulsion which, on administration, caused only a few acute side effects, and which seemed to be of great clinical value (Metabolism, 1957). This fat emulsion, Lipomul, was investigated extensively during the following years. As a result of certain side-effects, however, the manufacture of Lipomul was later discontinued.

Several reviews of intravenous fat emulsions have been published (Geyer, 1960; Schuberth \& Wretlind, 1961; Schön \& Zeller, 1962; Edgren \& Wretlind, 1963; Wretlind, 1964a). Papers dealing with recent experimental and clinical research in the field of intravenous fat emulsions were published in the American Journal of Clinical Nutrition in 1965.

A fat emulsion for intravenous nutrition usually contains a vegetable oil in water and one or two emulsifiers to stabilize the emulsion. A large number of fats or triglycerides have been studied during recent years. The five commercial fat emulsions, Infonutrol, Intralipid, Lipofundin, Lipomul and Lipiphysan, contain either cottonseed oil or soybean oil. As emulsifiers, different phosphatides are used. To obtain isotonicity with the blood, the water phase contains glucose, sorbitol or glycerol. The fatty acid compositions of the two oils differ. Soybean oil contains more linoleic acid and less saturated fatty acids than cottonseed oil. Soybean oil also contains linolenic acid, which is not found in cottonseed oil (Edgren \& Wretlind, 1963; Rose et al., 1965).

This paper will treat mainly of the experiences gained with the soybean oil-egg-yolk phosphatide emulsion. These emulsions contain $100 \mathrm{~g}$ or $200 \mathrm{~g}$ of fat, $12 \mathrm{~g}$ of egg-yolk phosphatides, and $25 \mathrm{~g}$ of glycerol per litre. Comparisons will be made between this emulsion and some cottonseed oil emulsions.

\section{Experimental studies}

There are many questions that must be answered 
before it is justifiable to use an artificial fat emulsion intravenously in man. Some of these questions are related to acute and chronic toxicity, utilization, dosage and comparison with chylomicrons of the chyle, which can be regarded as a physiological fat emulsion.

\section{Toxicity}

Emulsified low-molecular triglycerides, such as tributyrin and trinorvalerin affect the circulation and the respiration (Wretlind, 1957; Westerholm \& Wretlind, 1960). Only fat emulsions without such pharmacological effects can be employed. The commercial emulsions at our disposal today do not affect circulation and respiration. Some emulsions may cause unfavourable effects on the microcirculation in capillaries by aggregation of erythrocytes and fat particles (Brown et al., 1955; Bergentz, 1961; Bergentz, Gelin \& Rudenstam, 1961). No such effects have been observed in connection with the soybean oil emulsion (Gigon, Enderlin \& Scheidegger, 1966).

Before fat emulsions can be used for intravenous nutrition it is necessary to ensure that tolerance is sufficiently high. Investigations of acute toxicity by single infusions in rats and dogs have shown that emulsions can be given in amounts up to $15 \mathrm{~g} / \mathrm{kg}$ body weight without lethal effects. This means that the acute toxicity of these emulsions is very low and of no clinical importance. Single intravenous injections of the soybean oil emulsion given to man in doses up to $0.6 \mathrm{~g}$ fat $/ \mathrm{kg}$ during $2 \mathrm{~min}$ without causing any symptoms, have confirmed the very low acute toxicity (Hallberg, 1965b). Also single infusions of this emulsion given to man in doses of 3-4 g fat $/ \mathrm{kg}$ during 3-4 hr do not cause any symptoms.

The chronic toxicity or tolerance during long-term administration is of importance because, as a rule, there is a clinical demand for prolonged administration of fat emulsions. For long-term intravenous administration of fat, it is necessary to know that quantities corresponding to the caloric requirement are without toxic effects. Long-term infusions of cottonseed oil emulsions in man and in the dog have been stated to cause anorexia with loss of weight, vomiting, gastro-intestinal bleeding, hyperlipaemia, anaemia, thrombocytopenia and prolonged coagulation and prothrombin times (Artz, 1959; Preston \& Henegar, 1959; Werr \& Preston, 1959; Cohn et al., 1960). The anaemia is regarded as haemolytic (Loewy et al., 1943; Levenson, Upjohn \& Sheehy, 1957; Artz, 1959; Alexander \& Zieve, 1961). Liver damage and spontaneous bleeding may also occur (Artz, 1959; Cohn et al., 1960), consequently, these emulsions are not recommended for administration to man in doses exceeding $75 \mathrm{~g} \mathrm{fat} /$ day for 14 consecutive days. Such effects, called 'long-term reactions' or 'overloading syndrome', have not been described in connection with the $\stackrel{\frac{\$}{\alpha}}{\frac{2}{C}}$ soybean oil emulsion. However, changes in the $C$ coagulability of the blood during a single infusion $\overrightarrow{\vec{c}}$ have been observed (Amris, Brockner \& Larsen, 1964). These changes, reversible with heparin, have never been known to cause clinical symptoms. Anaemia has been observed after repeated fat emulsion infusions in man and in the dog (Collins et al., 1948; Mann et al., 1949; Upjohn, Creditor \& क Levenson, 1957; Kaley, Meng \& Bingham, 1959; $\vec{\circ}$ Cohn et al., 1960). There are great differences between the various emulsions.

Changes in the blood proteins and lipoproteins have been described. A decrease in the albumin concentration has been observed after prolonged infusions with cottonseed oil, whereas the concentration of lipoprotein was increased (Dohrman, Pezold \& Weller, 1959). It is difficult to determine whether these findings are toxic influences and/or a physiological response to the administration of fluid (Holm, 1965). Increase in lipoprotein concentration is also observed in man after the administration of chylomicrons (Hallberg, 1965e).

The blood-plasma potassium concentration is stated to decrease after fat administration (Baba, 1931; Marble et al., 1934). The other plasma electrolytes are not affected. The effect on potassium concentration has been considered favourable in the treatment of anuria, and is thought to depend on decreased cellular catabolism.

Dogs are well-suited for experimental studies on long-term tolerance for fat emulsions. With a moderate volume and amount of fat, the entire caloric requirement can be covered (corresponding to $9 \mathrm{~g} \mathrm{fat} / \mathrm{kg} / 24 \mathrm{hr}$ ). Dogs have also the advantage that side effects, such as nausea, vomiting, diarrhoea, etc., are easily recorded.

Studies on the tolerance in dogs for Lipomul and SR-emulsion $(15 \%$ cottonseed oil, stabilized with polyethylene glycolstearate and tartaric acid ester of monoglycerides) have been made (Cohn et al., 1960). The dogs survived $4.5 \mathrm{~g}$ fat $/ \mathrm{kg} 5$ days a week during 6 weeks. If larger doses of Lipomul were given the dogs died. The SR-emulsion became lethal with $7.5 \mathrm{~g}$ fat $/ \mathrm{kg}$. Similar results have been reported by Elster (1962) with Lipofundin in doses of 6-7 $\mathrm{g}$ fat $/ \mathrm{kg} /$ day given to ten dogs. All the dogs died in 7-8 days.

Edgren et al. studied Infonutrol and Intralipid in $\sigma$ dogs, with a dosage of $9 \mathrm{~g}$ fat $/ \mathrm{kg} /$ day for 4 weeks (Edgren et al., 1964). All dogs that received the soybean oil emulsion, Intralipid, survived. Berg et al. found no differences in toxicity between Lipofundin and Intralipid in studies on dwarf pigs (Berg et al., 1965).

The present study includes further tolerance investigations in dogs, which have been partly reported by Wretlind (Wretlind, 1964b) and 
Hakansson (1965). Infonutrol, Intralipid, Lipofundin and Lipiphysan were given in a dosage of $9 \mathrm{~g}$ fat $/ \mathrm{kg} /$ day over a planned experimental period of 28 days. The infusions were given during 4-5 hr with the dogs in a Pavlov stand. The effects on body weight, survival time and bleeding tendency are given in Fig. 1. All dogs receiving Intralipid survived in good condition and increased $14 \%$ in body weight. All the other dogs died before the end of the period. The survival time varied between 3 and 25 days. The last-mentioned dogs had marked symptoms from the overloading syndrome before

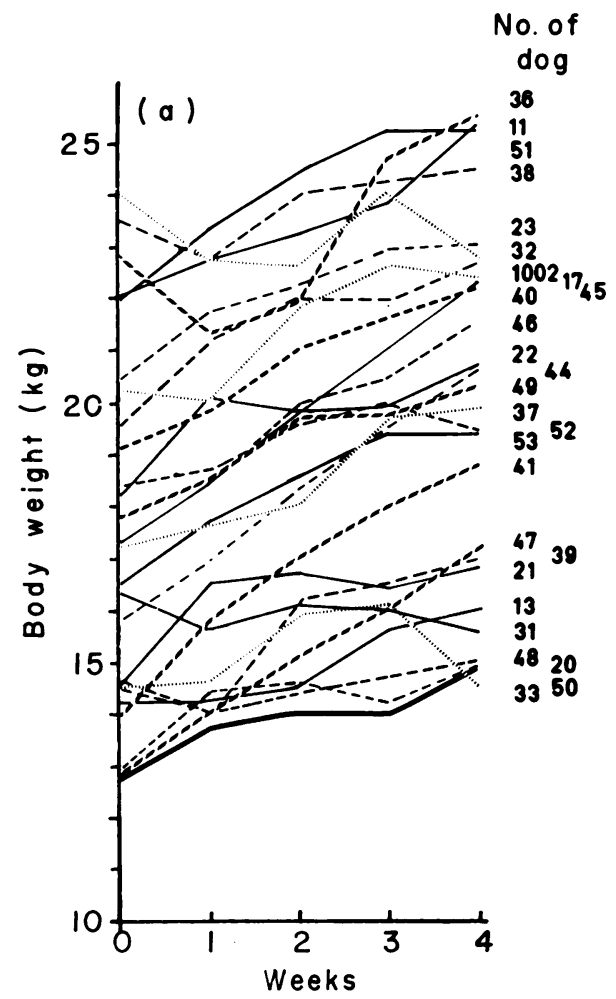

a greater increase in the plasma phosphatide concentration. With a reduction of the phosphatide concentration from $1.2 \%$ to $0.6 \%$ there was only a slight increase of the phosphatides and triglycerides in the blood. The number of white blood corpuscles increased when the cottonseed oil emulsions were administered, whereas the soybean oil emulsion caused only slight changes.

From this investigation it is obvious that the toxicity varies with the type of fat emulsion. The results show that dogs given the soybean oil emulsion survived in good condition, but all dogs receiving

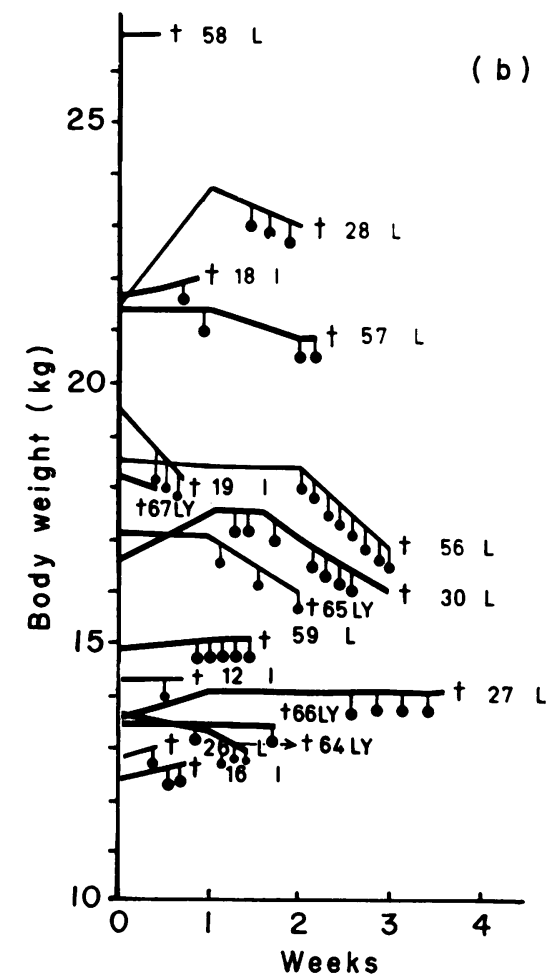

Fig. 1. Changes of body weight, bleeding and survival time in dogs given daily infusions of fat emulsions in amounts corresponding to $9 \mathrm{~g}$ fat $/ \mathrm{kg}$ for planned 28 consecutive days. (a) The soybean oil emulsion, Intralipid (average weight increase, $14 \pm 0.4 \%$ ). (b) The cottonseed oil emulsions, Infonutrol (I), Lipofundin (L) and Lipiphysan (LY); $O$, bleeding; $\dagger$, death.

death. 'Intravenous fat pigment' (see below) was found in the liver.

All animals receiving Intralipid were killed. The presence of the intravenous fat pigment in the liver, spleen and bone marrow was established. Signs of liver damage were not observed. In some cases, proliferation of reticulo-endothelial cells was found in the liver and spleen. The cottonseed oil emulsions caused more pronounced anaemia and a more elevated triglyceride and cholesterol content in the blood than did the soybean oil emulsion. On the other hand, the soybean oil emulsion brought about the cottonseed oil emulsions died under our experimental conditions.

\section{Morphological changes}

After long-term infusions of cottonseed oil emulsions in man and in the dog, ulcers in the stomach and duodenum have been observed (Jordan, 1957; Levenson et al., 1957; Artz, 1959; Werr \& Preston, 1959; Cohn et al., 1960; Hartwig et al., 1961). Liver disturbances with jaundice and abnormal bromsulphthalein-retention, as well as increased thymol turbidity and cephalin flocculation, 
were noted (Preston et al., 1957; Watkin, 1957). So far no such side effects have been recorded in connection with soybean oil-egg-yolk phosphatide emulsions.

The appearance of pigment in the liver and spleen of both man and animals after long-term fat infusions is interesting from a pathological point of view. Meyer et al. (1957) observed a brown pigment in the reticulo-endothelial system of patients and dogs treated repeatedly with cottonseed oil infusions. According to Thompson et al. (1960) this 'intravenous fat pigment' had not been described earlier. Intravenous fat pigment in the reticulo-endothelial cells has been observed also after soybean oil emulsions, but to a much less extent than with cottonseed oil emulsions (Thompson et al., 1965).

Numerous liver-function tests were performed (Thompson et al., 1965) in an attempt to assess the potential hazards which might be associated with large doses of emulsions, the deposition of intravenous fat pigments in the liver, the development of proliferative lesions or the alterations produced within hepatocytes. These included bromsulphthalein retention, radioactive colloidal gold uptake, radioactive rose bengal uptake and excretion, total bilirubin, direct bilirubin, serum alkaline phosphatase, micro-autoradiography of hepatocytes employing tritiated thymidine, serum lactic dehydrogenase, and serum glutamic pyruvic transaminase. It was not possible to demonstrate that large doses of emulsion, the intravenous fat pigment itself, proliferative lesions associated with its deposition or ultrastructural changes in hepatocytes, produced any impairment of liver function, either during the course of infusion or afterwards.

\section{Elimination from the blood stream}

Knowledge about the course of elimination of intravenous fat emulsions is of fundamental importance for two reasons. Firstly, in order to be able to give the correct amount of this nutrient, and, secondly and more theoretically, so as to understand the alimentary lipaemia and allied physiological and pathological problems. The latter statement is based on the fact that the artificial fat emulsion may have many similarities with chylomicrons, and can, for this reason, be used as a model in studies on chylomicron metabolism (Dole \& Hamlin, 1962; Boberg \& Carlson, 1964; Hallberg \& Wersall, 1964; Hallberg, 1965d).

The elimination of the triglycerides of fat emulsions and chylomicrons has been previously described as following an exponential or complex course (Carlson \& Hallberg, 1963). By means of studies in the dog and man, the kinetics of the elimination have been established in both (Hallberg, 1965d). No differences were observed either between the species or between the triglycerides in the soy- bean oil emulsion or the chyle isolated from the $\stackrel{\otimes}{\&}$ thoracic duct.

To demonstrate the elimination of fat particles from the blood, and the changes in the endogenous lipoproteins, it was necessary to separate the emulsion triglycerides from the endogenous plasmatriglycerides (Hallberg, 1964).

The changes in the endogenous plasma-trigly- $\propto$ cerides caused by the fat emulsion are interpreted as कै a recirculation of the infused triglycerides. This $\vec{\circ}$ recirculation indicates that the fat emulsion is utilized by metabolic processes. The changes in the $\vec{\omega}$ recirculating triglycerides are, with regard to $\frac{0}{0}$ magnitude and duration, dependent not only on the given dose of the fat emulsion (Hallberg, 1965a, b) but also on the nutritional and traumatic state ct (Hallberg, 1965c) of the patients.

The kinetics of the elimination of fat particles from the infused fat emulsion are as follows: Above a so-called 'critical concentration' there is a maximal elimination capacity. Below the "critical concentration' the elimination is dependent on the triglyceride concentration.

The mechanism for the removal of emulsiontriglycerides from the blood stream is unknown, but is assumed to depend on an enzyme (lipoprotein lipase), the amount of which determines the size of the maximal elimination capacity and the blood flow through the organ where that enzyme is located in the body. The size of the fraction of the total blood volume which passes the enzyme locations per unit of time determines the concentrationdependent elimination rate. The lipoprotein lipase activity has been investigated in vitro using different fat emulsions as substrates. There was no difference between Intralipid and chylomicrons but an obvious difference between all the other emulsions and the chylomicrons (Boberg \& Carlson, 1964).

The following quantitative findings on the elimination have been obtained for the soybean oil emulsion (Hallberg, 1965d).

(1) The elimination rate is independent of the dose.

(2) The maximal elimination capacity is significantly influenced by the nutritional state. The $\mathrm{N}^{\circ}$ capacity increases during starvation.

(3) In the traumatic state in man, both rate con- No stants are increased.

(4) The elimination of the fat emulsion from the $\bar{\sigma}$ blood stream causes changes in the endogenous 0 lipoprotein concentrations, which are increased.

The rate constants, for the elimination of the fat $\stackrel{\oplus}{\rightarrow}$ emulsion from the blood stream in man, permitted 0 calculation of the maximal dose per $24 \mathrm{hr}$. After an overnight fast $(15 \mathrm{hr})$ this was $0.07 \mathrm{~mm}$ fat $/ 1 \stackrel{\square}{\mathscr{Q}}$ plasma/min with a standard deviation of $\pm 0.03 \mathrm{~mm} / \stackrel{\mathbb{}}{\circ}$ $1 / \mathrm{min}(n=22)$. This value corresponds to $3.8 \mathrm{~g} \pm$ ? $1.6 \mathrm{~g}$ (SD) fat $/ \mathrm{kg}$ body weight $/ 24 \mathrm{hr}$. 


\section{Utilization of intravenously supplied fat}

Infusion of fat emulsion causes increased heat production, raised oxygen consumption, and lowered respiratory quotient, which indicate that the fat is metabolized (Baba, 1931; Meyer et al., 1957; Mueller, 1957). After the supply of ${ }^{14} \mathrm{C}$-marked fat, three-quarters of the ${ }^{14} \mathrm{C}$ can be found after a short time in the expired air (Geyer, Chipman \& Stare, 1948; Geyer et al., 1951). Weight and nitrogen balance can be obtained by giving an adequate nutritive supply together with intravenous fat emulsions (Mann et al., 1948; Meng \& Early, 1949; Krieger et al., 1957; Levine et al., 1957). A prolonged survival time, for starved dogs receiving intravenous fat emulsions, has been reported (Narat, 1937a, b). Our own experiments-reported below-with complete parenteral nutrition in the dog, where threequarters of the caloric need were covered by intravenous fat, also demonstrate that fat is utilized after intravenous administration.

The above investigation and other studies provide strong evidence that intravenously supplied fat is utilized.

\section{Complete parenteral nutrition in dogs}

Tolerance studies of fat emulsions have been carried out in connection with complete parenteral nutrition in the dog using approximately the same method as that described by Meng \& Early (1949). In the present study the different nutrients were administered in the amounts shown in Table 1

\section{TABLE 1}

Amount of calories and nutrients per day and $\mathrm{kg}$ body weight during complete parenteral nutrition in the dog

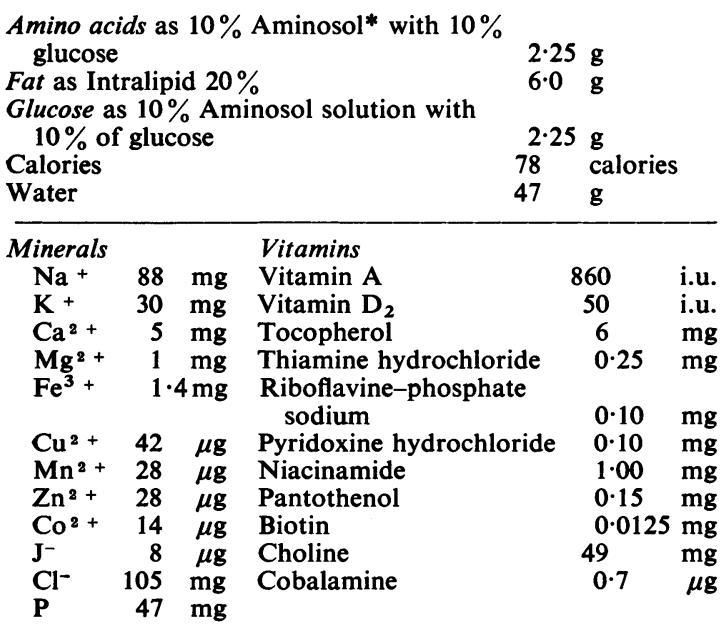

Vitamin A and D, tocopherol and choline were included in the Intralipid emulsion. All other vitamins, minerals, and electrolytes were added to the Aminosol solution.

* Vitrum, Stockholm, Sweden.
(Hakansson, Holm \& Wretlind, 1965). About threequarters of the caloric requirement were given as fat. The infusions were given daily for about $6 \mathrm{hr}$ with the dogs in Pavlov stands. Four dogs were given complete parenteral nutrition for a experimental period of 10 weeks. At the end of the period all the dogs were in excellent condition. The dogs gained weight during the experimental period. The haemoglobin content, haematocrit, red cell count and plasma proteins changed only slightly. The triglyceride, phosphatide and cholesterol content increased to a moderate extent (Hakansson et al., 1965). The nitrogen, sodium, potassium and calcium balances were positive during the period. At autopsy, the day after the experiments had concluded, no macroscopic changes were observed in the organs, except for duodenal ulcers in one of the dogs. The microscopic investigation showed intravenous fat pigment, haemosiderin and fat particles in the reticulo-endothelial cells. In one dog some miliary necroses of liver cells were demonstrable. This dog was in a good condition and showed no signs of illness before being killed.

These investigations have thus demonstrated that dogs can be kept in good condition for a long time wholly by intravenous administration of nutrients.

\section{Conclusions from experimental studies}

A great number of different fat emulsions have been investigated. The available fat emulsions had very few acute side-effects. However, they showed great differences in long-term tolerance. Some of them produced lethal effects. The properties of soybean oil emulsion were such that the total caloric requirement could be covered in the dog for 4 weeks without side reactions. This fat emulsion was eliminated from the blood stream at the same rate as chylomicrons in dog and man. Intravenous fat pigment in the reticulo-endothelial cells was observed in connection with all the emulsions. Complete parenteral nutrition with the soybean oil emulsion could be given to dogs for a period of 10 weeks.

\section{Clinical studies}

A large number of different fat emulsions, which passed the acute toxicity tests, were used in clinical studies. Schuberth \& Wretlind (1961) and Schuberth (1963a) reported on such clinical studies in man. It was later shown that only one of the emulsions, Intralipid, satisfied all the demands, including chronic toxicity tests. Since 1960 we have restricted our clinical investigations to this emulsion. In order to determine the incidence of acute side-effects and long-term reactions, a large number of infusions have been given in man. Clinical studies were also made to show the utilization of the infused fat and the possibility of using the intravenous fat emulsions for long-term, complete, parenteral nutrition in man. 


\section{Materials}

In 1963 a study of 1086 infusions of the soybean oil emulsion was reported (Schuberth, 1963b). The present material is an extension of that study to 2781 infusions. The infusions have been given to surgical and geriatric patients, under strict control, by a special nurse.

\section{Results}

Acute side reactions. Most acute reactions were manifested as rise in temperature. No such reactions occurred in $97.3 \%$ of 2781 infusions. Chills were noted in about $1 \%$ of the infusions. Most of them occurred some hours after the end of the infusions. These reactions were never serious. The incidence of rise in temperature and chills seems to be independent of the amount of fat given.

Other acute side effects were a sensation of warmth, shivering without fever, vomiting, pain in chest and back, and thrombophlebitis. A sensation of warmth was the most frequent side effect $(8 \%)$. This subjective sensation, however, was manifested only in a moderate degree, and never caused discomfort. The very low incidence (one case) of thrombophlebitis was impressive. We are under the impression that the relatively high incidence of thrombophlebitis in connection with highly concentrated amino acid or glucose solutions is eliminated when these infusions are given simultaneously with fat emulsion. This phenomenon may be regarded either as merely the result of dilution, or due to the protective influence of the emulsion on the vascular endothelium.

Long-term reactions. Most of the patients given more than fifteen infusions have been controlled by means of laboratory analyses, such as haemograms, liver function tests, electrolytes and coagulation tests. No evidence of any unfavourable effects was observed but a transitory prolongation of the retention of bromsulphthalein and a slight increase in transaminase values was noted in some cases. To summarize, it may be inferred that Intralipid can be infused in doses corresponding to $2 \mathrm{~g}$ fat $/ \mathrm{kg}$ body weight/day over a long period with only slight risk of acute untoward reactions. Not a single case of overloading syndrome has been observed.

Utilization. It is difficult to estimate the clinical effect of supplying calories in the form of fat emulsion. One way is to assess the overall impression of the patient's general condition (Freuchen \& Ostergaard, 1964). On the other hand, it is desirable to estimate to what extent patients will benefit from adequate intravenous nutritional therapy. Whether the caloric supply is adequate can be determined by its effect on the nitrogen balance. A positive or lessnegative nitrogen balance means that the caloric source is utilized. In this test it is necessary to give a basal amount of 100-150 $\mathrm{g}$ of carbohydrate. A substantially reduced nitrogen loss, by infusion of $\frac{\mathbb{D}}{\varrho}$ fat, glucose and casein hydrolysate, has been shown $\complement$ by many authors (Abbott \& Albertsen, 1963; $;$ Krieger et al., 1957; Larsen \& Brockner, 1965;Wadström \& Wiklund, 1964). Scharli (1964) had no등 difficulty in obtaining a positive nitrogen balance $\overline{\bar{c}}$. in man by using amino acids in combination with $\overparen{\Phi}$ calories as dextrose (about 500 calories) and Intra- $\frac{\varrho}{\nu}$ lipid (about 1200 calories).

The effect of Intralipid on nitrogen balance in the $\vec{\circ}$ post-operative period after gastrectomy, was studied $-\overrightarrow{-}$ in twenty cases (Schuberth, unpublished). The $\tilde{N}^{-}$ patients were divided into three groups, which received various amounts of fat, carbohydrates and 3 amino acids. The results are shown in Fig. 2. The

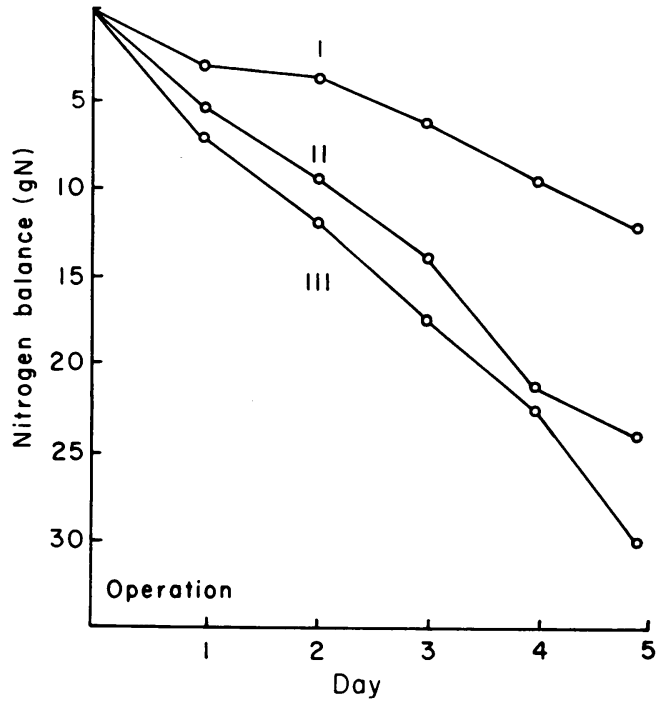

FIG. 2. Cumulative nitrogen loss during the 5 first post-operative days after partial gastrectomy in cases with duodenal ulcer. Group I consisted of eight patients receiving 36 calories, $1.5 \mathrm{~g}$ amino acids, $2 \mathrm{~g}$ fat and 3 $\mathrm{g}$ glucose/kg body weight/day: group II, eight patients with 15 calories, $1.5 \mathrm{~g}$ amino acids and $2.2 \mathrm{~g}$ glucose: group III, four patients with 16 calories and $4.0 \mathrm{~g}$ glucose.

nitrogen loss during the first five post-operative days $\frac{D}{2}$ was largest with an intravenous supply of only $16 \mathrm{cal} / \mathrm{kg}$ body weight, in the form of glucose, and $\stackrel{N}{\circ}$ no amino acids (III). With 15 calories and $1.5 \mathrm{~g}$ of amino acids the nitrogen loss was less (II). The N smallest nitrogen loss occurred with 36 calories, $2 \mathrm{~g}$ of fat, $3 \mathrm{~g}$ of glucose and $1.5 \mathrm{~g}$ of amino acids per $\mathrm{kg}$ body weight and day (I). This indicates that the fat supplied had a nitrogen-sparing effect.

Long-term infusions. During recent years a number of long-term infusions of Intralipid have been given to clinical patients to maintain complete parenteral nutrition including glucose and amino acids as Aminosol. The longest period of parenteral nutrition was that given to a patient suffering from Crohn's disease, with several abdominal fistulae. He 
received 2-2.5 $\mathrm{g}$ of fat, $0 \cdot 4-6 \cdot 2 \mathrm{~g}$ of glucose and up to $1.2 \mathrm{~g}$ of amino acids per $\mathrm{kg}$ body weight per day regularly for more than 5 months (Fig. 3). The total amount of fat administered was $15,040 \mathrm{~g}$. The general condition of the patient improved although nutrition by mouth was impossible and in spite of the fluid losses through the fistulae of the small intestine. Control of the patient including all the abovementioned tests, revealed no disturbances of any kind. Liver biopsy was performed after $4 \frac{1}{2}$ months cases where caloric requirements cannot be covered by means of oral nutrition or tube feeding. In some instances there may be a need to supply fat parenterally as a supplement to an ordinary diet. The following aspects may be emphasized:

(1) Pre-operative conditions. As a result of prolonged nutritional disturbances the general condition of a patient may be affected to such an extent that an improvement is necessary before major surgical measures can be undertaken. In such cases it is

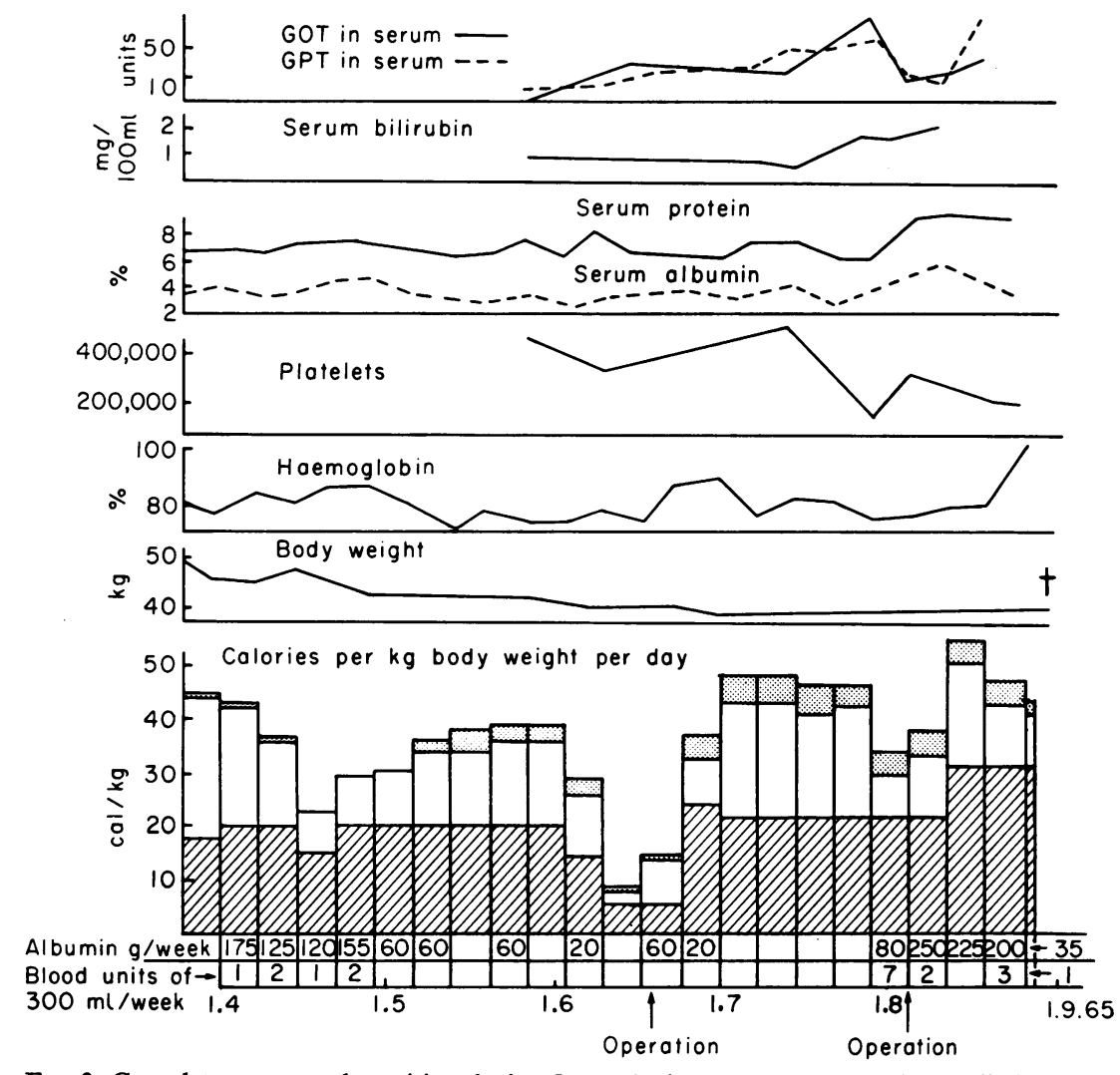

FIG. 3. Complete parenteral nutrition during 5 months in a 22-year-old patient suffering from Crohn's disease. The diagram shows the amount of fat $(20 \%$ Intralipid) (cross-hatched columns), amino acids ( $10 \%$ Aminosol) (stippled columns) and glucose (unshaded columns) given. The changes in body weight, haemoglobin, platelets and concentration of protein, albumin, bilirubin and transaminases (GOT, GPT) in serum are also recorded in the chart.

of parenteral therapy. The histological examination showed no evidence of any abnormality. He died 1 month later of his primary disease. Without parenteral nutrition it would not have been possible to keep this patient alive for such a long time.

\section{Conclusions}

\section{Indications}

We consider infusion of fat emulsion, together with amino acids and carbohydrates, is indicated in often of value to administer generous quantities of calories and nitrogen preoperatively.

(2) Post-operative conditions. Oral nutrition or tube-feeding is often difficult in the post-operative phase. In these conditions, including pre-operative nutritional disturbances, it is advisable to start parenteral nutrition on the 1st day after the operation by giving fat in doses up to $2 \mathrm{~g} / \mathrm{kg}$ body weight in addition to carbohydrates and amino acids. Thus, the patient will be in a better condition, and the 
risk of complications in the post-operative phase will be reduced. In less critical cases it is advisable to use intravenous administration of fat emulsion, together with carbohydrates and amino acids, if the patient cannot take food by mouth on the 4th or 5th post-operative day.

(3) Conditions with reduced or interrupted intestinal absorption. Serious enteritides and ulcerative colitis may be favourably affected by large supplies of calories at an early stage. In this context, cases with intestinal fistulae, with low utilization of food taken by mouth as a consequence, should be particularly emphasized.

(4) Burns. The large caloric requirements of cases with burns must be given due consideration. Even if alimentation by mouth is possible, it appears that parenteral therapy with fat as a supplement to carbohydrates and amino acids is to be recommended, especially in serious cases. The considerable loss of fluid through evaporation from burned surfaces shown by Kinney (1960), increases the caloric need. Each litre of water that evaporates means a caloric requirement of 576 calories. The use of fat emulsions is the only way to provide an appropriate amount of calories to patients with burns.

(5) Prolonged unconsciousness may be an indication for complete parenteral nutrition when tube feeding is contraindicated.

(6) Various forms of cachexia, e.g. anorexia nervosa, may sometimes call for parenteral nutrition. It is also conceivable that cachexia, due to general carcinomatosis or comparable conditions, would, in some cases, be an indication for parenteral nutrition, and fat emulsion should then be used.

(7) In anuria, when it is important to limit the supply of fluid, the administration of a large amount of calories in small quantities of fluid may be valuable (Alwall, 1964; Kille \& Lawson, 1964) and others have used fat emulsions in uraemic and anuric patients with and without dialysis. In this way it was possible to keep the patients in a fairly good nutritional condition and to reduce the loss of body weight and body protein.

\section{Contra-indications}

Pathological hyperlipaemia is a contra-indication to the use of fat emulsion. Liver damage and blood diseases with coagulation disturbances have been discussed as contra-indications. The limited experience makes it difficult to give more precise recommendations.

\section{Recommendations}

Fat emulsions are given as ordinary drip infusions. We have developed a convenient method for simultaneous administration of the different solutions. Separate drip chambers are used for fat emulsion and for solutions containing $10 \%$ of carbohydrates and $10 \%$ of amino acids. The two infusion sets are connected by a Y-shaped joint piece, so that the $e^{\complement}$ combination of fat emulsion and amino acids or carbohydrates enters the venous bloodstreanf through the same cannula.

Table 2 shows our schedule for complete paren $\frac{\bar{y}}{\bar{v}}$ teral nutrition to cover basal and high requirements of calories, amino acids, carbohydrates, and fat. $\varrho$ The solutions and the amounts of these are givens in Table 3. The infusion rate should not exceed 5 $0.5 \mathrm{~g}$ fat $/ \mathrm{kg}$ body weight $/ \mathrm{hr}$.

TABLE 2

Recommended daily allowance of water, calories, amino 3 acids, carbohydrate and fat for complete parenteral nutrition

\begin{tabular}{|c|c|c|}
\hline & \multicolumn{2}{|c|}{ Per kg body weight per day to cover } \\
\hline & $\begin{array}{c}\text { Basal } \\
\text { requirements }\end{array}$ & $\begin{array}{l}\text { High } \\
\text { requirements }\end{array}$ \\
\hline $\begin{array}{l}\text { Water } \\
\text { Calories } \\
\text { Amino acids } \\
\text { Glucose or fructose } \\
\text { Fat }\end{array}$ & $\begin{array}{rl}25-35 & \mathrm{ml} \\
25-30 & \text { calories } \\
1 \mathrm{~g} \\
2 \mathrm{~g} \\
2 \mathrm{~g}\end{array}$ & $\begin{array}{rl}50-60 & \mathrm{ml} \\
50-60 & \text { calories } \\
2 & \mathrm{~g} \\
5 \mathrm{~g} \\
3 \mathrm{~g}\end{array}$ \\
\hline
\end{tabular}

TABLE 3

Amount of solutions for complete intravenous nutrition to cover basal and high metabolic requirements

\begin{tabular}{|c|c|c|c|c|}
\hline \multirow[t]{2}{*}{ Solutions } & \multicolumn{2}{|c|}{$\begin{array}{l}\text { Basal require- } \\
\text { ments (ml) in a } \\
\text { patient with a } \\
\text { body weight of: }\end{array}$} & \multicolumn{2}{|c|}{$\begin{array}{l}\text { High require- } \\
\text { ments (ml) in a } \\
\text { patient with a } \\
\text { body weight of: }\end{array}$} \\
\hline & $50 \mathrm{~kg}$ & $70 \mathrm{~kg}$ & $50 \mathrm{~kg}$ & $70 \mathrm{~kg}$ \\
\hline $\begin{array}{l}20 \% \text { fat emulsion } \\
20 \% \text { glucose or fructose }\end{array}$ & 500 & 700 & 750 & 1050 \\
\hline $\begin{array}{l}\text { solution } \\
10 \% \text { amino acid }\end{array}$ & 500 & 700 & 1250 & 1750 \\
\hline solution & 500 & 700 & 1000 & 1400 \\
\hline
\end{tabular}

When using complete parenteral alimentation iț is necessary to give adequate amounts of water, calories, amino acids, electrolytes and vitamins. 0 The practice is first to determine the amount of fluid which should be given according to the circumstances in the particular case. Then the questiono arises how to administer the different nutrients ind adequate amounts with the determined quantity of ${ }^{\circ}$ fluid. If the patient can be given large amounts of fluid, there are fewer problems. But when restricted $\frac{d}{\mathrm{D}}$ fluid supply is necessary, it is difficult to satisfy the? patient's calorie requirements. In most cases it wili be a question of giving the patient adequate amounts of nutrients in a fairly small amount of fluid. 
Recently, fat emulsions have been produced, and these have given more opportunities for providing adequate parenteral alimentation with moderate amounts of fluid, because of the higher caloric value of the fat.

The commercially available fat emulsions contain either cottonseed oil or soybean oil. Experimental studies show that the acute side-effects with these are few. There are great differences, however, in tolerance for repeated infusions of larger quantities. We found that all cottonseed oil emulsions examined in dogs gave lethal effects in quantities which correspond to the caloric needs, whereas the soybean oil emulsion, Intralipid, in an amount of $9 \mathrm{~g}$ fat $/ \mathrm{kg}$ body weight/day, could be administered over a period of 4 weeks without serious side-effects. Moreover, experiments in dogs were carried out with complete intravenous nutrition during a period of 10 weeks. In these experiments three-quarters of the caloric requirement were covered by fat in the form of a soybean oil emulsion. Throughout this period the dogs were in good condition.

The kinetics of the elimination of soybean oil emulsion from the blood stream were investigated. No differences were observed for the elimination of triglycerides from chylomicrons and those from the artificial fat emulsion. The rate of elimination was independent of the dose. The maximal elimination capacity increased after fasting.

A large number of investigations in animals and man have shown that intravenous fat emulsions are well utilized in the body.

A report is given on 2781 infusions of Intralipid in man. In $97 \cdot 3 \%$ no pyrogenic complications were recorded. In $1 \%$ of the infusions, chills were recorded. In a separate study on 235 selected patients chills were observed in $0.85 \%$.

In twenty-eight patients more than fifteen consecutive infusions were given. A transitory increase of bromsulphthalein retention was noted in some cases, but no other side effects were observed.

The main indications for fat infusions are conditions when complete oral nutrition cannot be maintained, for example pre- and post-operative conditions, severe enteritides, ulcerative colitis, burns, prolonged unconsciousness, various forms of cachexia, and renal insufficiency.

The following recommendations are given for intravenous feeding: 1-2 $\mathrm{g}$ of amino acids, 2-3 $\mathrm{g}$ of fat as a soybean oil emulsion, and 2-5 $\mathrm{g}$ of glucose or fructose per $\mathbf{k g}$ body weight per day. According to the results of our investigations, these amounts can be given for long periods. One patient, who suffered from Crohn's disease, received daily infusions of 2-2.5 $\mathrm{g}$ of fat, $0.4-6.2 \mathrm{~g}$ of glucose and up to $1.2 \mathrm{~g}$ of amino acids per $\mathrm{kg}$ body weight for more than 5 months without any signs of side reactions.

\section{References}

Abbotr, W.E. \& Albertsen, K. (1963) Intravenous protein alimentation. Nutr. et Dieta (Basel), 5, 339.

Alexander, C.S. \& Zieve, L. (1961) Fat infusions: Toxic effects and alterations in fasting serum lipids following prolonged use. Arch. intern. Med. 107, 514.

AlWall, N. (1964) Abstracts First World Fat Congress, Hamburg 1964, p. 251.

American Journal of Clinical Nutrition (1965) Symposium on fat emulsions. 16, 1-224.

Amris, C., Brøckner, J. \& Larsen, V. (1964) Changes in the coagulability of blood during infusion of intralipid. Acta chir. scand. Suppl. 325, 70.

ARTZ, C.P. (1959) Newer concepts of nutrition by the intravenous route. Ann. Surg. 149, 841.

BABA, T. (1931) Uber den Abbau direct infundierten Fetts im Tierkörper; Grundumsatz pankreasdiabetischen Tier nach Fettinfusion. Tohoku J. exp. Med. 17, 154.

BerG, G., Zeller, W., RüGHeimer, E. \& ElSTER, K. (1965) Untersuchungen über Toxigatät und Verträglichkeit von Fettemulsionen an Zwergschweinen. Arzneimittelforshung, 15, 1472.

BERgentz, S.E. (1961) Studies on the genesis of post traumatic fat embolism. Acta chir. scand., Suppl. 282, 1.

Bergentz, S.E., Gelin, L.-E. \& Rudenstam, C.-M. (1961) Fats and thrombus formation. An experimental study. Thrombos. Diathes. haemorrh. (Stuttg.), 5, 474.

Boberg, J. \& CARLSON, L.A. (1964) Determination of heparin-induced lipoprotein lipase activity in human plasma. Clin. chim. Acta, 10, 420.

Brown, C.E., Trahan, H., Zinsser, H.H., Ware, A.G. \& SLANKeR, R.C. (1955) Evaluation of an intravenous fat emulsion in depleted blood volume states. West. J. Surg. 63, 723.

Carlson, L.A. \& Hallberg, D. (1963) Studies on the elimination of exogenous lipids from the blood stream. The kinetics of the elimination of a fat emulsion and of chylomicrones in the dog after single injection. Acta physiol. scand. 59, 52.

Cohn, I., Atik, M., Hartwig, Q.L., Cotlar, A.M., MoreLAND, J. \& WERNER, J.C. (1960) Experience with prolonged administration of intravenous fat emulsions. $J$. Lab. clin. Med. 55, 917.

Collins, H.S., Kraft, L.M., Kenney, T.D., Davidson, C.S., Young, J. \& STARE, F.J. (1948) Parenteral nutrition. III. Studies on the tolerance of dogs to intravenous administration of fat emulsions. J.Lab. clin. Med. 33, 143.

Dohrman, R., Pezold, F.A. \& Weller, H. (1959) Das Verhalten der serumlipide und lipoproteide frisch operierter während intravenöser Fettinfusionen; vorläufige Mitteilung. Klin. Wschr. 37, 704.

Dole, V.P. \& Hamlin, J.T. (1962) Particulate fat in lymph and blood. Physiol. Rev. 42, 674.

Edgren, B., Hallberg, D., Hakansson, I., Meng, H.C. \& WretLind, A. (1964) Long term tolerance study of two fat emulsions for intravenous nutrition in dogs. Amer. J. clin. Nutr. 14, 28.

EDGRen, B. \& WretLind, A. (1963) The theoretical background of the intravenous nutrition with fat emulsions. Nutr. et Dieta (Basel), 5, 364.

ElsTer, K. (1962) Vorträge anlässlich der Tag. d. Dtsch. Ges. Fettwissensch. e.V. Fachgruppe X Klinische Biologie der Fette, Düsseldorf, Oktober 1962, p. 47. Pallas, Lochham/München.

Freuchen, J. \& OstergaArd, J. (1964) Parenteral nutrition in surgical patients. Acta chir. scand., Suppl. 325, 55.

GeYer, R.P. (1960) Parenteral nutrition-fat emulsion for parenteral use. Physiol. Rev. 40, 150.

Geyer, R.P., Chipman, J. \& Stare, F.J. (1948) Oxidation in vivo of emulsified radioactive trilaurin administered intravenously. J. biol. Chem. 176, 1469. 
Geyer, R.P., Waddell, W.R., Pendergast, J. \& Yee, G.S. (1951) Oxidation of lipides $\left(\ldots \mathrm{C}^{14} \mathrm{OO} \ldots\right)$ in vivo by extrahepatic rat tissues. J. biol. Chem. 190, 437.

Gigon, J., Enderlin, F. \& Scheidegger, F. (1966) Schweiz. med. Wschr. 96, 71.

HAKANSSON, I. (1965) Nutr. et Dieta (Basel) 7, 90.

Hakannsson, I., Holm, I. \& Wretlind, A. (1965) Nutr. et Dieta (Basel), 7, 241.

Hallberg, D. (1964) Studies on the elimination of exogenous lipids from the blood stream. Determination and separation of the plasma triglycerides after single injection of a fat emulsion in man. Acta physiol. scand. 62, 407.

Hallberg, D. (1965a) Studies on the elimination of exogenous lipids from the blood stream. The kinetics of the elimination of a fat emulsion studied by a constant infusion technique in man. Acta physiol. scand. 64, 299.

Hallberg, D. (1965b) Studies on the elimination of exogenous lipids from the blood stream. The kinetics of the elimination of a fat emulsion studied by single injection technique in man. Acta physiol. scand. 64, 306.

HALlBeRG, D. (1965c) Studies on the elimination of exogenous lipids from the blood stream. The effect of fasting and surgical trauma in man on the elimination rate of a fat emulsion injected intravenously. Acta physiol. scand. 65, 153.

Hallberg, D. (1965d) Elimination of exogenous lipids from the blood stream. Acta physiol. scand. 65, Suppl. 254.

HallberG, D. (1965e) Studies on the elimination of exogenous lipids from the blood stream. The kinetics for the elimination of chylomicrons studied by single intravenous injections in man. Acta physiol. scand. 65, 279.

HALlBerg, D. \& Wersäll, J. (1964) The electron-microscope investigation of chylomicrons and fat emulsions for intravenous use. Acta chir. scand. Suppl. 325, 25.

Hartwig, W.L., Cotlar, A.M., Shelby, J.S., Atik, M. \& CoHN, I. (1961) Tolerance to intravenously administered fat emulsions. Surgery, 49, 308.

HODDER, E. (1873) Transfusion of milk in cholera. Practitioner, 10, 14.

HoLM, I. (1965) The effect on the plasma proteins of peroral, enteral, intraportal and intravenous administration of casein hydrolysate. Acta chir. scand. Suppl. 351, 4.

JORDAN, P.H. (1957) Intravenous administration of an improved fat emulsion. Observations of the effects of storage upon the incidence of reactions. Metabolism, 6, 656.

Kaley, J.S., Meng, H.C. \& Bingham, C. (1959) Some haematological changes in patients receiving multiple infusions of fat emulsions. Amer. J. clin. Nutr. 7, 652.

Kille, J.N. \& LAwson, L.J. (1964) Parenteral Nutrition Colloquium, London.

KINNEY, J.M. (1960) Influence of intermediary metabolism on nitrogen balance and weight loss: some considerations basic to an understanding of injury. Bull. N.Y. Acad. Med. 36, 377.

Krieger, H., AbbotT, W.E., Levey, S. \& Holden, W.D. (1957) The use of a fat emulsion as a source of calories in patients requiring intravenous alimentation. Gastroenterology, 33, 807.

LARSEN, V. \& BROCKNER, J. (1965) Nitrogen balance and operative stress. Acta chir. scand. Suppl. 343, 191.

LeVenson, S.M., UpJohN, H.L. \& SHeEHY, T.H. (1957) Two severe reactions following the long term infusion of large amounts of intravenous fat emulsion. Metabolism, 6, 807.

Levine, R.S., Calvary, E.C., Plzak, J.E. \& Allen, J.G. (1957) Effect of parenterally administered fat emulsions on nitrogen retention: attempts at complete parenteral alimentation in dogs. Metabolism, 6, 597-606.

Loewy, A., Freeman, L.W., Marchello, A. \& Johnson, V. (1943) Increased erythrocyte destruction on a high fat diet. Amer. J. Physiol. 138, 230.

ManN, G.V., Geyer, R.P., Watkin, D.M., SMythe, R.L., DJU, D.C., ZAMCheCK, N. \& StaRe, F.J. (1948) Parenteral nutrition. VII. Metabolic studies on puppies infused with fat emulsions. J. Lab. clin. Med. 33, 1503.
Mann, G.V., Geyer, R.P., Watkin, D.M. \& Stare, F.备 (1949) Parenteral nutrition. IX. Fat emulsions for intrae venous nutrition in man. J. Lab. clin. Med. 34, 699.

Marble, A., Field, M.E., Drinker, C.K. \& SMith, R.M (1934) The permeability of the blood capillaries to lipids Amer. J. Physiol. 109, 467.

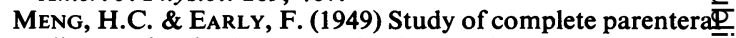
alimentation in dogs. J. Lab. clin. Med. 34, 1121.

Meng, H.C. \& Freeman, S. (1948) Experimental studieब on the intravenous injection of a fat emulsion into dogs? J. Lab. clin. Med. 33, 689.

Metabolism (1957) Clinical experience with intravenous fat emulsions. Symposium on intravenous fat emulsion. 6, 591.

Meyer, C.E., Fancher, J.A., Schnurr, P.E. \& Webster, H.D. (1957) Composition, preparation and testing of afy intravenous fat emulsion. Metabolism, 6, 591.

MUELLER, J.F. (1957) Experiences in human beings with am improved fat emulsion for intravenous administration? J. Lab. clin. Med. 50, 257.

NARAT, J.K. (1937a) Observations on parenteral adminis tration of fat emulsions. Amer. J. digest. Dis. 4, 107.

NARAT, J.K. (1937b) Uber intravenöse Fetteinspritzungeṇo Arch. klin. Chir. 187, 795.

Preston, F.W., Barnes, A.U., Mandel, E.E., Staley C.J. \& TRIPPEL, O.H. (1957) Effects of repeated infusions of a fat emulsion in surgical patients. Metabolism, 6, 758?

Preston, F.W. \& Henegar, G.C. (1959) Use of intravenous fat emulsions in surgical patients. Surg. Clin. N. Amero $39,143$.

Rose, A., Pelick, N., Angeloni, F.M. \& Miller, M.E(1965) Analysis of intravenous fat emulsions and coms ponents. Amer. J. clin. Nutr. 16, 4.

Scharli, A. (1964) Praxis, 53, 1215.

SCHÖN, H. \& ZELLER, W. (1962) Nutr. et Dieta (Basel)o Suppl. ad 4, 1.

SCHUBERTH, O. (1936a) Berl. Med. 14, 235.

SCHUBERTH, O. (1936b) Clinical results of intravenou@ infusion of fat emulsions. Nutr. et Dieta (Basel), 5, 387. 으

SCHUBERTH, O. \& WRETLind, A. (1961) Intravenous infusion? of fat emulsions, phosphatides and emulsifying agents $\overrightarrow{\vec{D}}$ Acta chir. scand. Suppl. 278, 1.

Thompson, S.W., Fox, M.A., Forbes, A.L. \& Thomassen, R.W. (1960) Residual pigment associated with intravenous fat alimentation. Amer. J. Path. 36, 355.

Thompson, S.W., Jones, L.D., Ferrell, J.E., Hunt, R.D. Meng, H.C., Kuyana, T., Sasaki, H., Schaffner, F. Singleton, W.S. \& CoHN, J. (1965) Testing of fat emulsions for toxicity. III. Toxicity studies with new faㅡ. emulsions and emulsion components. Amer. J. clin. Nutro $16,43$.

Upjohn, H.L., Creditor, M.C. \& Levenson, S.M. (1957) Metabolic studies of intravenous fat emulsions in normab and malnourished patients. Metabolism, 6, 607.

WAdSTRöM, L.B. \& WikLUND, P.E. (1964) Effect of fat emulsions on nitrogen balance in the post-operative period. Acta chir. scand. Suppl. 325, 50.

WATKIN, D.M. (1957) Clinical, chemical, haematologic and anatomic changes accompanying repeated intravenousu administration of fat emulsion to man. Metabolism, 6, 785 응

Wentzel, A. \& Perco (1896) Wien. med. Wschr. 19, 517.

Werr, J.A. \& Preston, F.W. (1959) Effect of an intra venous fat emulsion on blood coagulation. Arch. Surge 79, 213.

Westerholm, P. \& Wretlind, A. (1960) The effect of trinorvalerin on circulation and respiration. Acta phar macol. (Kbh.), 17, 44.

WretLind, A. (1957) The toxicity of low molecular trio glycerides. Acta physiol. scand. 40, 59.

WretLind, A. (1964a) The pharmacological basis for the use of fat emulsions in intravenous nutrition. Acta chir $\varrho$ scand. Suppl. 325, 31.

WretLind, A. (1964b) Abstracts First World Fat Congress Hamburg, p. 254. 